\title{
Uso del color en la infancia
}

\section{Use of color in childhood}

\author{
Dominga González *, Encarnación Sueiro** \\ *Universidad de Vigo, **C.O.F. Nóvoa Santos (SERGAS-Ourense)
}

\begin{abstract}
Resumen
En las preferencias de colores que tienen los niños y las niñas pueden percibirse estereotipos de género, responsables de la diferenciación entre colores masculinos, femeninos y neutros. Así lo demuestran los resultados obtenidos en dos investigaciones llevadas a cabo en las etapas de Educación Infantil y Primaria acerca del uso de los colores en la infancia. De ambas investigaciones se hablará en el presente trabajo, así como también de todo lo referente al color y a los procesos de percepción y concepción de los colores en la infancia, entre los cuatro y los siete años de edad.

Palabras clave: color, infancia, estereotipos, género.
\end{abstract}

\begin{abstract}
In the preferences of colors that children have can be perceived gender stereotypes, which are responsible for the differentiation between masculine, feminine and neutral colors. This is demonstrated by the results obtained in two researches carried out in the stages of Early Childhood and Primary Education about the use of colors in childhood. From both investigations we will speak in the present work, as well as everything related to color and the processes of perception and conception of colors in childhood, between four and seven years of age. Keywords: color, childhood, stereotypes, gender.
\end{abstract}

\section{Introducción}

Los colores son uno de los primeros conocimientos que adquieren las niñas y los niños y están presentes en todos los aspectos de su vida cotidiana: ropa, juguetes, mobiliario de su habitación, accesorios de cuidado personal, etc. Desde el primer momento en el que llega al mundo, un bebé va a estar expuesto a una gran variedad de colores presentes en su entorno. Pero, a medida que

va creciendo, empezará a mostrar preferencia por unos más que por otros. Dichas preferencias en cuanto al color van a estar condicionadas por el contexto en el que se percibe el mismo. Como dice Heller (2004): "Ningún color carece de significado. El efecto de cada color está determinado por su contexto, es decir, por la conexión de significados en la cual percibimos el color". En el contexto entran en juego diferentes factores como son los medios de comunicación, las familias, el entorno social más cercano,... que influyen de forma importante en las preferencias de colores de cada niño/a. Y como resultado de estas influencias pueden aparecer y consolidarse los estereotipos de género relacionados con el color. Un claro ejemplo de ello es la idea que viene fomentándose desde hace décadas acerca de que el color rosa es para las niñas y el color azul para los niños.

A lo largo del presente trabajo se explicarán, primeramente, unas ideas generales en relación a los colores, su clasificación y su simbología. Seguidamente, se analizarán los procesos importantes que se dan entre los 4 y 7 años de edad en relación a la concepción del color. También se hará referencia a la teoría del aprendizaje social en la preferencia y uso de los colores. Finalmente, se explicarán dos investigaciones destacadas sobre el uso de los colores por niños y niñas de preescolar y de los primeros cursos de Educación Primaria. Ambas investigaciones fueron un punto importante de motivación para realizar un tercer estudio del cual se hablará en un trabajo posterior que lleva por título: "Color y sexo".

\section{El color}

Autores destacados en las teorías sobre el color. En este apartado podemos mencionar a cinco intelectuales que se interesaron por el tema de los colores y que hicieron importantes contribuciones a este ámbito.

El físico Isaac Newton (1642-1727) estudió el color desde una perspectiva científica, revelando por primera vez en la historia de la ciencia, que la luz solar se compone de una mezcla de colores. Según él, la luz reflejada por un prisma de cristal puede descomponerse en siete colores: rojo, naranja, amarillo, verde, azul, índigo y violeta.

A diferencia de Newton, Juan Goethe (1749-1832) estudió el color desde una perspectiva psicológica, prestando especial atención al efecto que producía el color sobre la percepción y la conducta humana. Los estudios que realizó en este ámbito, llevaron a Goethe a la conclusión de que los colores son parte de nuestra visión, y que por lo tanto, son una percepción sensorial antes que nada.

Influenciado por las ideas de Goethe, el pintor alemán Phillip Otto Runge (1777-1810) diseñó una disposición de los colores en una esfera, la cual fue uno de los 
primeros modos de clasificación de los colores, antecesor del círculo cromático actual. En el círculo cromático actual aparecen representados, de forma ordenada y circular, los colores primarios y sus combinaciones para dar lugar a los demás colores visibles.

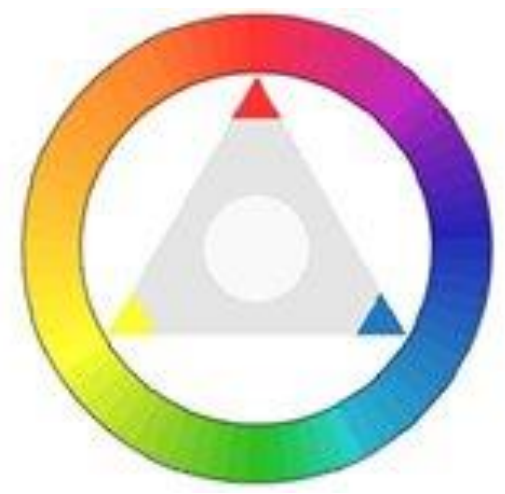

Figura 1. Círculo cromático.

El pintor francés Eugène Delacroix (1798-1863) tuvo una influencia importante en los impresionistas debido al uso que hacía de los contrastes entre colores complementarios en sus obras.

Otro pintor destacado es Vincent Van Gogh (18531890), considerado uno de los mayores genios de la historia del arte, que acogió con mucho interés las teorías referentes al color.

\section{Clasificaciones de los colores}

Los colores se pueden clasificar en función de varios criterios, como la intensidad, la claridad o la calidez.

La intensidad o saturación del color se refiere a su grado de cromatismo o colorido. Si el grado de cromatismo es máximo, se trataría de un color intenso, mientras que se hablaría de un color atenuado para el caso contrario, cuando la apariencia es enturbiada y difuminada.

En relación a la claridad, lo que diferencia a un color claro de un color oscuro es, básicamente, la luminosidad. Un color será más claro cuanto más luminosidad presente, y viceversa.

$\mathrm{Si}$ se habla de las emociones que una persona experimenta en función del color percibido se puede diferenciar entre colores cálidos y colores fríos. Como afirma Pawlik (1996): "Los colores frios expresan arrobamiento, distanciamiento, transfiguración, incluso distinción contenida; los cálidos aproximación, recogimiento, intimidad, estrechez terrenal. La lejanía contiene colores más fríos que la cercanía”.

Otra clasificación de los colores es la que diferencia entre colores primarios y secundarios. Los tres colores primarios son el rojo, el amarillo y el azul; y de las combinaciones entre ellos surgen los colores secundarios (violeta, naranja y verde).

\section{Simbología de los colores}

Dependiendo de cada persona, las sensaciones que evoca cada uno de los colores van a ser diferentes. Por ello, como resultado de estas diversas sensaciones, a lo largo del tiempo las sociedades han atribuido unos símbolos generales a los colores. Se trata de símbolos de carácter subjetivo y mutable, pues al igual que las modas, a lo largo del tiempo los colores pueden causar impresiones diferentes. La simbología de los colores presenta diferencias entre las diferentes culturas existentes. Así por ejemplo, mientras que el verde se considera un símbolo de esperanza en nuestra cultura, en China soñar con dicho color se interpreta como una señal de augurio.

A nivel general se puede hacer referencia a los principales significados que se le atribuyen a los diferentes colores. Por ejemplo, el color amarillo se asocia mucho con la iluminación y la luz. Por otra parte, el naranja es considerado un color llamativo y exótico, que evoca diversión. El azul, considerado un color frío, en la antigua simbología se asociaba a lo femenino, pues aparecía, por ejemplo, en los mantos de la Virgen; mientras que hoy en día está vinculado a lo masculino, por ser el color del que se viste a los niños recién nacidos. El verde, el color de la esperanza y de la primavera, evoca también tranquilidad. El rojo se considera, principalmente, el color de la pasión, de la fuerza y de la actividad. Derivado del rojo, está el color rosa, hoy en día asociado a lo femenino, pero que tiene una simbología pasada asociada a lo masculino. Ejemplos de ello son la impresión en papel rosado de un diario deportivo italiano, La Gazetta dello Sport, leído casi de forma exclusiva por hombres, y los cuadros de los siglos XIII, o mismo del siglo XIX, donde aparece pintado el Niño Jesús con vestimenta de color rosa. El color violeta es considerado el color del feminismo y también es símbolo de magia. Por último, el color lila, muy parecido al violeta, también se asocia a lo femenino, pues aparece con frecuencia en los envases y en las cajas de los cosméticos destinados a la mujer.

\section{Acercamiento a los colores en la infancia (4-7 años)}

Etapas en el proceso de concepción del color en la infancia (4-7 años) En el período que comprende las edades de entre 4 y 7 años se dan importantes avances en relación al proceso de concepción del color. GarcíaBermejo (1978) diferencia en dicho período dos grandes etapas, que a su vez comprenden otras fases. Se trata de la etapa cromática básica sobre el descubrimiento del color (2-6 años) y la etapa cromática básica de sistematización del color (7-9 años).

La etapa cromática básica del descubrimiento del color incluye cinco fases: la del garabato negro (2-3 años), la de la mancha, que pude ser negra o coloreada (3 años), la del garabato coloreado (4-5 años), la de distinción del colorante la forma (5 años) y la de identificación de los colores (6 años). La fase del garabato coloreado supone una importante evolución con respecto a las fases anteriores, pues las niñas y los niños sustituyen al garabato negro por el garabato a color. En un principio parece que emplean un determinado color para cada tipo de forma, como si se tratase de una asociación difícil de separar para ellos/as, por ejemplo: color rojo para manchas circulares. Pero a los 5 años surge ya la fase de distinción del color ante la 
forma. Y en la última fase de esta etapa cromática básica del descubrimiento del color, a los 6 años de edad, las niñas y los niños establecen ya las primeras relaciones entre los colores y los dibujos que hacen.

A partir de los 7 años de edad, se inicia la otra etapa cromática básica, la de sistematización del color. Dicha etapa abarca cuatro fases: la de comparación de los colores (7 años), la de sistematización cromática central (8 años), la de preferencia de colores (también a los 8 años) y la de iniciación de la relación color-objeto real (9 años). En la fase de comparación de los colores, como bien indica su nombre, tiene lugar el establecimiento de comparaciones entre unos colores básicos- que suelen ser los que primero se eligen- y otros que surgen del contraste o de la combinación de esos colores básicos. Posteriormente, a lo largo de las siguientes fases, las preferencias de colores de niños y niñas se irán modificando de acuerdo a nuevos criterios adquiridos.

\section{Teoría del aprendizaje social en la preferencia y uso de los colores}

Por influencia del entorno social, el aprendizaje de los colores en la población infantil no está libre de ser "contaminado" por estereotipos de género, lo que va a condicionar también las preferencias que cada persona puede tener hacia los diferentes colores. Un ejemplo de ello es la idea que se tiene de que el color rosa es para las niñas y el color azul para los niños. Las pequeñas y los pequeños, inconscientemente, son influenciados por las ideas extendidas socialmente y aprenden las conductas que supuestamente son las "correctas". A este tipo de aprendizaje en el que influye de forma importante la sociedad que nos rodea se le denomina aprendizaje social.

Albert Bandura (1984), en su teoría acerca del aprendizaje social, a la hora de hablar de los orígenes de la conducta diferencia entre un aprendizaje debido a las consecuencias de la respuesta y un aprendizaje por observación de modelos. En el primero, el aprendizaje debido a las consecuencias de la respuesta, una conducta se repetirá o no dependiendo de los efectos positivos o negativos que produce la misma. En cambio, en el aprendizaje por observación existe un modelo del cual se observa su conducta para seguidamente aprenderla. En este tipo de aprendizaje intervienen procesos de atención, de retención, de reproducción motora y, por supuesto, procesos motivacionales, dentro de los cuales están las consecuencias positivas o negativas que produce la conducta en el modelo que la está ejecutando.

Por lo tanto, niñas y niños, desde edades tempranas, aprenderán bajo la influencia, primeramente, de sus padres y familiares y, seguidamente, de las personas con las que vayan interactuando a medida que crecen, como por ejemplo los amigos y el personal de colegio. Y también serán influenciados/as por las ideas y opiniones que se expanden a través de los medios de comunicación. Lo mismo ocurre en el caso del aprendizaje de los colores: color de la ropa que compran los padres a sus hijos/as, colores que se utilizan en el colegio, colores de juguetes que se anuncian por la televisión para cada sexo, etc.

\section{Investigaciones sobre el uso de los colores en Educación Infantil y Primaria}

Estudio de Rachel Karniol (2011). Este trabajo de investigación se aplicó a una muestra de 98 niñas y niños israelís de preescolar y de los tres primeros cursos de Educación Primaria (6-9 años). El objetivo era analizar su comportamiento ante una tarea de colorear, la cual presentaba una figura estereotipada masculina, una femenina y otra neutra. En el momento de aplicación de las pruebas se les presentaron dos tipos de cuadernos para colorear, de los cuales solo tenían que elegir uno, en función de la portada: fondo rosa con imagen de Batman o fondo azul con imagen de muñeca Bratz. A continuación, se les pidió que coloreasen tres tipos de dibujos, contenidos en los dos tipos de cuadernos: un hada de dibujos animados, el personaje de Ben 10 y cinco estrellas. Para la tarea de colorear se les ofrecieron ocho pinturas, cuatro de las cuales eran de colores considerados "masculinos" (verde claro, verde oscuro, azul claro y azul oscuro) y otras cuatro de colores considerados "femeninos" (rosa, rojo, malva y morado). Las pruebas fueron realizadas con el grupoclase y no hubo límite de tiempo. La única condición que se puso a la hora de colorear fue que las estrellas debían ser pintadas cada una de un color diferente.

En cuanto a los resultados obtenidos, a la hora de elegir la portada de los cuadernos, la mayoría escogió teniendo en cuenta antes el dibujo que el color de fondo. En lo referente a la variedad de los colores usados en las figuras del hada y de Ben 10, quienes participaron utilizaron más colores para pintar aquella figura que era de su mismo sexo. Para pintar la figura de Ben 10, los participantes de ambos sexos emplearon colores similares. Pero la diferencia se notó en la figura del hada y en las estrellas, donde los niños utilizaron menos colores "femeninos" que las niñas.

El estudio presentó algunas limitaciones importantes: no se emplearon colores "neutros", las pruebas fueron pasadas con todo el grupo-clase (posibilitando la influencia entre iguales a la hora de elegir los colores) y el hecho de que pudiesen conocer los colores asociados a las figuras que tenían que colorear (hada y Ben 10) limitaba su utilización libre de los colores.

Estudio de Raúl Navarro, Elisa Larrañaga, Verónica Martínez y Santiago Yubero (2014). Se trata de una réplica del estudio de Karniol (2011), pero aplicado en España, con 614 participantes de un colegio de Cuenca, de edades comprendidas entre 5 y 10 años. Par mejorar ciertos aspectos del estudio de Karniol, se dividió la muestra en dos partes. A una de ellas se le pasaron unas pruebas idénticas a las que se habían pasado en el estudio precedente, mientras que para la otra parte se introdujeron algunas modificaciones: las dos figuras sexuadas para colorear eran diferentes y se ofrecieron dos pinturas más. En lugar de las figuras del hada y de Ben 10, conocidas por los participantes, se presentaron los dibujos de un niño y de una niña. Y los dos colores nuevos que se introdujeron fueron el amarillo y el naranja, considerados "neutros". De esta 
forma, una parte de los participantes pudieron utilizar diez colores, en lugar de ocho.

Las pruebas fueron pasadas también con el grupoclase y no hubo límite de tiempo. La única condición que se planteó fue que las cinco estrellas debían ser pintadas cada una con un color diferente.

Al igual que en el estudio precedente, en los resultados obtenidos la mayoría de las y los participantes escogieron la portada en función de la ilustración que contenía, más que por el color de fondo. A la hora de colorear, los niños utilizaron menos los colores considerados "femeninos" (rosa, rojo, malva y morado), en comparación con las niñas; y evitaron, especialmente, el uso del color rosa. En esto influyó, por una parte, la introducción de los dos colores neutros, que podrían sustituir al color rosa. Los participantes de ambos sexos colorearon en cada figura con los colores estereotipados asociados con ellos: colores "femeninos" para la figura de la niña y colores "masculinos" para la figura del niño. Mientras que en el dibujo de las estrellas lo destacable fue que las niñas pintaron con menos colores "femeninos".

La principal limitación de este estudio de Navarro y sus colaboradores fue que las pruebas se siguieron pasando con el grupo-clase de forma simultánea, lo que podría influir en las elecciones de los colores que hacía cada participante, al estar en contacto con sus iguales.

\section{Referencias}

Bandura, A. (1984). Teoría del aprendizaje social. Madrid: Espasa-Calpe, S. A.

Cohen, P. N. (2013). Children's Gender and Parents' Color Preferences. Arch Sex Behav, 393-397.

Heller, E. (2004). Psicología del color. Barcelona: Gustavo Gili D. L.

Karniol, R. (2011). The Color of Children's Gender Stereotypes. Sex Roles, 119-132.

Navarro, R., Martínez, V., Yubero, S., \& Larrañaga, E. (2014). Impact of Gender and the Stereotyped Nature of Illustrations on Choice of Color: Replica of the Study by Karniol (2011) in a Spanish Sample. Gend. Issues, 142-162.

Pawlik, J. (1996). Teoría del color. Barcelona: Paidos Ibérica S.A.

Pizarro, S. G.-B. (1978). El color en el arte infantil. Madrid.Varichon, A. (2009). Colores. Historia de su significado y fabricación. Barcelona: Gustavo Gili, SL. 